\title{
Efficacy of Anti-TNF Therapy for the Treatment of Patients with Moderate-to-Severe Inflammatory Bowel Disease; a First Iranian Report
}

\author{
Samaneh Mohagheghi Darehranj ${ }^{1}$, Sudabeh Alatab ${ }^{1, *}$, Homayoon Vahedi ${ }^{1}$, Anahita Sadeghi ${ }^{1}$, Alireza \\ Sima ${ }^{1}$, Masoud Malekzadeh ${ }^{1}$, Amir Anoshiravani ${ }^{1}$, Hafez Fakheri ${ }^{2}$, Nasser Ebrahimi Daryani ${ }^{3}$, \\ Abdolhamid Mousavi ${ }^{4}$, Fariborz Mansour-Ghanaei ${ }^{5}$, Mohammad Javad Zahedi ${ }^{6}$, Reza Malekzadeh ${ }^{1}$
}

1. Digestive Disease Research Center, Digestive Disease Research Institute, Tehran University of Medical Sciences, Tehran, Iran

2. Gut and Liver Research Center, Mazandaran University of Medical Sciences, Sari, Iran

3. Department of Gastroenterology, Imam Khomeini Hospital, Tehran University of Medical Sciences, Tehran, Iran

4. Gastroenterology Department, Hormozgan Medical School, Hormozgan University of Medical Sciences, Hormozgan, Bandar-Abbas, Iran

5. Gastrointestinal and Liver Diseases Research Center, Guilan University of Medical Sciences (GUMS), Rasht, Iran

6. Digestive Research Center, Kerman University of Medical Sciences, Kerman, Iran

* Corresponding Author:

Sudabeh Alatab, MD, PhD

Digestive Disease Research Institute, Shariati Hospital, Tehran University of

Medical Sciences, Tehran, Iran.

North Kargar Street, Shariati Hospital,

Digestive Diseases Research Institute.

Postal code: 1411713135

Tel: + 982182415215

Fax: + 982182415400

Email: sudabehalatab@yahoo.com

Received: 01 Jul. 2019

Accepted: 10 Dec. 2019

\section{ABSTRACT}

\section{BACKGROUND}

The anti-TNF drugs are shown to be highly effective in treatment of patients with moderate-tosevere inflammatory bowel disease (IBD). Here, we aimed to assess the efficacy and safety of antiTNF therapy at the national level.

\section{METHODS}

IBD patients aged $15>$ years who received Infliximab and/or CinnoRA ${ }^{\circledR}$ between 2013 to July 2018 were identified. The data extracted from medical dossier and telephonic interview. The efficacy of therapy was defined as time to drug discontinuation or need for IBD-related surgery. The safety was assessed based on patient's reported adverse events.

\section{RESULTS}

We included 315 patients. The mean age of patients was 37.2 years and $62.2 \%$ of them developed the disease before age 30 years. Involvement of masculoskeletal system was reported in $7.3 \%$ of patients. Partial and complete response to Anti-TNF therapy was seen in $67 \%$ of patients. About $16 \%$ of patients did not respond to induction therapy and $16.9 \%$ of patients lost their response to Anti-TNF during one year. No serious adverse events, serious opportunistic infection, tuberculosis and malignancies reported by patients. Two patients reported pneumonia.

\section{CONCLUSION}

This study for the first time in our country, provides the evidences for efficacy of anti-TNF therapy in moderate to severe IBD patients.

\section{KEYWORDS:}

Inflammatory Bowel disease, Anti-TNF drug, Infliximab, CinnoRA ${ }^{\circledR}$

\section{Please cite this paper as:}

Mohagheghi Darehranj S, Alatab S, Vahedi H, Sadeghi A, Sima A, Malekzadeh MM, Anoshiravani A, Fakheri H, Ebrahimi Daryani N, Mousavi SH, Mansour-Ghanaei F, Zahedi MJ, Malekzadeh R. Efficacy of Anti-TNF Therapy for the Treatment of Patients with Moderate-to-Severe Inflammatory Bowel Disease; a First Iranian Report. Middle East J Dig Dis 2020;12:12-18. doi: 10.15171/mejdd.2020.158.

\section{INTRODUCTION}

Inflammatory bowel disease (IBD), with two main subtypes of crohn's disease (CD) and ulcerative colitis (UC), is a chronic idiopathic inflammation of the intestines with a relapsing - remitting nature. Although the underlying cause of IBD is unclear, but it seems that a combination of interactions between the genetic 
backgrounds, alterations in the composition of the intestinal microbiota, environmental factors and dysregulation in innate and adaptive immune system trigger an aberrant immune response causing an impaired mucosal barrier function and consequently disease development. ${ }^{1-2}$ The new epidemiological studies propose that epidemiology of IBD is changing all around the world and the disease might be rapidly rising in countries from South America, Asia and even Africa. ${ }^{3}$ Recent published studies from our country also stressed on rise of incidence cases of IBD from 0.62 to 3.11 per 100,000 population from 1990 to $2012 .{ }^{4}$ IBD could produce a heavy burden on society due to a decrease in the quality of life of the patients and an increase in disability. Naghavi et al. estimated that in our country, the burden of GI diseases ranked $7^{\text {th }}$ among all other diseases at $2003 .^{5}$

The main goal of therapeutic options in IBD patients is to reduce the inflammation and symptoms of the disease and improve the recovery of intestinal tissue. With advances in the understanding of the pathological mechanisms underlying IBD, new therapies have been proposed with the most important development being the introduction of antitumor necrosis factor (TNF) agents. ${ }^{6-10}$ These drugs have been used in treatment of patients with moderate-to-severe forms of IBD refractory to conventional treatments. ${ }^{11}$ The basic mode of actions of these drugs involve use of antiinflammatory cytokines, neutralization of pro-inflammatory cytokines and inhibition of neutrophil adhesion. ${ }^{12}$ While researches showed that employment of these drugs is associated with a reduced need for surgery and hospitalization and an improvement in quality of life, ${ }^{11}$ but these treatments have not been effective in all patients, and some patients either do not respond to these medications or those who initially responded might lost their responsiveness over time. ${ }^{11,13-16}$

Currently, the most commonly used anti-TNF agents are infliximab (IFX) and adalimumab (ADA). IFX (Remicade, Janssen and MSD/Merck), the first biological agent approved by FDA for treatment of moderate to severe UC, is a $149,100-\mathrm{d}$ chimeric monoclonal antibody directed against TNF- $\alpha .{ }^{17}$ Another drug, ADA (Humira ${ }^{\circledR}$, AbbVie, USA), is a fully human monoclonal antibody consists of two identical heavy and two identical light chains that bind specifically to the transmembrane TNF and blocks the interaction of TNF- $\alpha$ with its receptor. ${ }^{18-19}$ ADA was first approved by the US-FDA for the treatment of
Rheumatoid Arthritis and then for other conditions including IBD. ${ }^{19}$ In our country "CinnoRA ${ }^{\circledR}$ " was developed by CinnaGen Company as a biosimilar to the ADA product.

Globally, several studies have investigated the clinical effects and potential side effects of these drugs in IBD patients. However, because of relative novelty of employment of TNF inhibitor agents in our country, no study has been done so far to evaluate the efficacy of these medications at national level. In this study, we evaluated the response rate and patient's reported adverse events of IFX and CinnoRa ${ }^{\circledR}$ used in moderate-to-severe IBD patients in a retrospective manner.

\section{MATERIALS AND METHODS}

\section{Study design}

This study was designed as an observational and retrospective study of a real time case series of patients with moderate to severe UC or CD who went under treatment with an anti-TNF agents (IFX and/or CinnoRA $($ ) from 2013 (time when drug became available in Iran ) to July 2018. The participants were drawn from the list of Iranian Registry of Crohn's and Colitis. The diagnosis was established by their physicians based on the clinical, radiological, pathological and laboratory examinations. The study was performed at Digestive Disease Research Institute (DDRI) of Tehran University of Medical Sciences and the study protocol was approved by the ethics committee of DDRI and the participants signed their informed consent.

The inclusion criteria were: patients (both sexes) aged $\geq 15$ years with moderate to severe UC (Mayo score $>6)$ or CD $(150<$ Crohn's Disease Activity Index < $450)$ that were either refractory to conventional therapy, or were steroid-dependent or steroid unresponsiveness and used CinnoRA ${ }^{\circledR}$, and/ or IFX as part of their treatment regimen.

Patients considered refractory to treatment when they received standard therapy (two to three of these drug lines: prednisolone, azathioprine/6-mercaptopurine (AZT/6-MP) and 5-aminosalicylates (5-ASA) but showed poor response.

CinnoRA $\AA$ was injected based on the following protocol: $160 \mathrm{mg}$ at week $0,80 \mathrm{mg}$ at week 2 as induc- 
Table 1: Baseline characteristics of study patients

\begin{tabular}{|c|c|}
\hline Characteristics & $\mathrm{N}=\mathbf{3 1 5}$ \\
\hline Age (year), mean (SD) & $37.2(12.2)$ \\
\hline \multicolumn{2}{|l|}{ Age category, n (\%) } \\
\hline$\leq 30$ years & $101(32.1)$ \\
\hline$>30$ & $214(67.9)$ \\
\hline \multicolumn{2}{|l|}{ Sex, n (\%) } \\
\hline Male & $151(47.9)$ \\
\hline Female & $164(52.1)$ \\
\hline \multicolumn{2}{|l|}{ Education, n (\%) } \\
\hline Illiterate Elementary & $6(1.9)$ \\
\hline High school & $\begin{array}{c}14(4.4) \\
120(381)\end{array}$ \\
\hline University & $175(55.6)$ \\
\hline \multicolumn{2}{|l|}{ Marital status, n (\%) } \\
\hline Single & $102(32.4)$ \\
\hline Married & $231(67.6)$ \\
\hline \multicolumn{2}{|l|}{ Cigarette smoking, n (\%) } \\
\hline Never & $294(93.3)$ \\
\hline Previous or currently & $21(6.7)$ \\
\hline Positive family history of IBD, n (\%) & $54(17.1)$ \\
\hline \multicolumn{2}{|l|}{ Comorbidity, n (\%) } \\
\hline Liver Disease & $15(4.8)$ \\
\hline Hypertension & $25(7.9)$ \\
\hline Diabetes Mellitus & $6(1.9)$ \\
\hline $\begin{array}{l}\text { Time from diagnosis to data collection } \\
\text { (year), mean (SD) }\end{array}$ & $8.7(6.5)$ \\
\hline Age at diagnosis (year), mean (SD) & $28.4(11.7)$ \\
\hline \multicolumn{2}{|l|}{ Disease diagnosis, $\mathrm{n}(\%)$} \\
\hline Crohn's disease & $154(48.9)$ \\
\hline Ulcerative colitis & $161(51.1)$ \\
\hline \multicolumn{2}{|l|}{ Site of Crohn's disease, n (\%) } \\
\hline Ileum & $44(28.6)$ \\
\hline Colon & $44(28.6)$ \\
\hline Ileocolon & $55(35.7)$ \\
\hline Unknown & $11(7.1)$ \\
\hline \multicolumn{2}{|l|}{ Site of Ulcerative Colitis, n (\%) } \\
\hline Ulcerative proctitis & $43(26.7)$ \\
\hline Left sided colitis & $3(1.9)$ \\
\hline Pancolitis & $76(47.2)$ \\
\hline Unknown & $39(24.2)$ \\
\hline \multicolumn{2}{|l|}{ Extra intestinal manifestation, $\mathbf{n}(\%)$} \\
\hline Masculoskeletal & $23(7.3)$ \\
\hline Deramtological & $13(4.1)$ \\
\hline Ocular & $6(1.9)$ \\
\hline Hepatobiliary & $15(4.7)$ \\
\hline Anti-TNF therapy(year), mean (SD) & $2.5(0.8)$ \\
\hline
\end{tabular}

tion, and then $40 \mathrm{mg}$ every 2 weeks for maintenance therapy. IFX with dose of $5 \mathrm{mg} / \mathrm{kg}$ diluted in $250 \mathrm{ml}$ $0.9 \% \mathrm{NaCl}$ and infused intravenously over a period of at least 2 hours as an induction regimen at 0,2 and 6 weeks followed by a maintenance regimen of $5 \mathrm{mg} / \mathrm{kg}$ every 8 weeks thereafter.

\section{Variable analyzed}

The data obtained by means of a questioner as well as patient's medical record. The trained interviewer from our center called the patients and obtained the necessary information based on a predefined questionnaire. The variable obtained included: gender, age, disease duration up to time of interview, smoking status, comorbidities, family history of IBD, history of appendectomy, extent of disease, IBD related surgery (if any), extraintestinal manifestations, drug treatment history, type and duration of anti-TNF therapy, drug switching, cause of discontinuation of anti-TNF treatment and patient's reported adverse events. Patients were considered to be primary non responder to anti-TNF therapy if their treatment was discontinued by physicians before 12 weeks of therapy in case of using CinnoRA $\AA$ and before 14 weeks in case of using IFX. The willingness of patient to terminate the therapy or occurrence of side effects as a reason for treatment discontinuation did not included in the analysis. The secondary loss of response was defined as either using the anti-TNF-agents for less than 52 weeks but more than 12 weeks for CinnoRA ${ }^{\circledR}$ and 14 weeks for IFX, or need for IBD related surgery. Patients who used the anti-TNF therapy for more than 52 weeks considered as responder.

\section{Statistical analysis}

The results of the variables were described with the mean, medium, minimum, maximum value and standard deviation (quantitative variables) or as frequency and percentage (categorical variables). Data were analyzed using SPSS version 16 software package. $p$ values $<0.05$ were considered as statistical significant.

\section{RESULTS}

Among 700 patients that fulfilled the eligibility criteria, we could provide the complete information and consent form for 315 patients (figure 1).

Patient demographic and disease characteristics are summarized in table 1 . The mean age of participants was 37.2 years (range 14 to 70 years). Female subjects comprised $52.1 \%$ of our study group. Only $6.7 \%$ of our study subjects used cigarette during their life time. The mean duration of disease was 8.7 years ( 1 to 41 years). The IBD age onset was 28.4 years. Involvement of masculoskeletal 


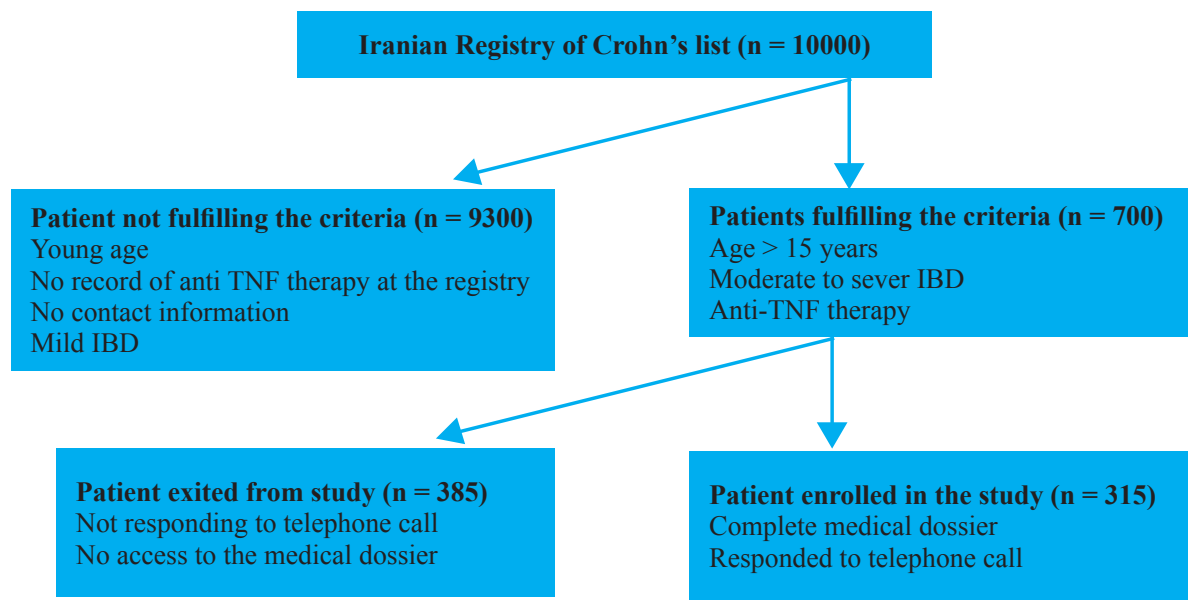

Fig.1: Flow chart of study selection process

Table 2: The medical profile of the study subjects

\begin{tabular}{lcc}
\hline & \multicolumn{2}{c}{ Anti-TNF Therapy } \\
\cline { 2 - 3 } & Single therapy, $\mathbf{n}(\%)$ & Switched therapy, $\mathbf{n}(\%)$ \\
\hline CD, n (\%) & $121(75.6)$ & $39(24.4)$ \\
\hline UC, n (\%) & $120(77.4)$ & $35(22.6)$ \\
\hline CD \&UC, n (\%) & $241(76.5)$ & $75(23.5)$ \\
\hline
\end{tabular}

system was reported in $7.3 \%$ of patients. UC patients' number were slightly higher than $\mathrm{CD}$ patients $(51.1 \%$ vs $48.9 \%$ ). The most common involved site in $\mathrm{CD}$ was Ileocolon (35.7\%) and majority of UC patients had involvement of total colon (47.2\%).

Looking at the profile of anti-TNF therapy showed that the majority of subjects $(n=241,76.5 \%)$ treated with only one TNF- $\alpha$ inhibitor agent (table 2) and this figure did not significantly differ between $\mathrm{CD}$ and UC patients (75.6\% vs $77.4 \%$ respectively). About $23.5 \%$ of subjects $(n=75)$ needed the switching from one antiTNF blocking agent to another and again this figure did not differ between CD and UC patients (table 2).

The response of patients to anti-TNF therapy was assessed based on the drug consumption duration, as was explained in method section (table 3 ). The average time of Anti-TNF therapy for patients was 2.5 years (table 1). About $16.05 \%$ of our subject did not respond to therapy before 12 weeks of therapy in case of using CinnoRA ${ }^{\circledR}$ and before 14 weeks in case of using IFX and categorized as primary non responder. The percent of primary non responder was not different between UC and CD patients. The percent of patients who lost their response to
Anti-TNF during one year period (secondary non responder) was slightly higher in UC patients (18.3\%) compared to CD patients (15.6\%). For $67 \%$ of patients the anti-TNF therapy continued beyond one year and these patients were categorized as responder. The percent of responder patients was not significant different between $C D$ and UC patients. We could not find any correlation between gender $(p=0.93)$, disease type $(p=0.14)$, and age $(p=0.95)$ with response rate to anti-TNF therapy.

Due to retrospective nature of this study we could not get comprehensive and validated results regarding the adverse events following anti-TNF therapy. Most of the reported adverse events were mild and included the redness and pain at the site of injection. No serious adverse events occurred during the study period. A total of 25 minor adverse events potentially related to the procedure were reported by 18 patients. Two patients reported the development of pneumonia. None of our patients reported the serious infection, tuberculosis and malignancies. None of our patients needed surgery while were on AntiTNF therapy.

\section{DISCUSSION}

Anti-TNF agents have advanced the management of IBD and are regarded as the mainstay for inducing and maintaining remission in patients with moderate to severe IBD. The use of these drugs is associated with decreasing the risk of surgery, hospitalization and diseaserelated complications, however, around 10-30\% of patients do not respond to the initial treatment and some 
Table 3: Subgroup analysis by IBD type

\begin{tabular}{|c|c|c|c|c|}
\hline & \multicolumn{3}{|c|}{ IBD type } & \multirow{2}{*}{$\begin{array}{c}p \text { value } \\
\text { Switched therapy, } \\
\text { n }(\%)\end{array}$} \\
\hline & CD & $\mathbf{U C}$ & Total & \\
\hline Primary non-responder to Anti-TNF blocking agents & $16.3 \%$ & $15.8 \%$ & $16.05 \%$ & NS \\
\hline Secondary loss of response to Anti-TNF blocking agents & $15.6 \%$ & $18.3 \%$ & $16.9 \%$ & NS \\
\hline Responder to Anti-TNF blocking agents & $68.1 \%$ & $65.9 \%$ & $67 \%$ & NS \\
\hline
\end{tabular}

of patients that initially responded to treatment might lose their response over time. Moreover there are some adverse events associated with consumption of Anti-TNF therapy including infusion reactions, blood disorders and bacterial, viral, fungal and opportunistic infections.

This study reports on a nationwide experience regarding the safety and efficacy of Anti-TNF therapy in moderate to severe IBD patients. Our results confirm the efficacy of anti-TNF agents in inducing and maintaining clinical remission in a majority of patients with moderate or severe IBD who were either corticosteroid-dependent or had failed previous therapy with steroids and/or immunosuppressive drugs. To our knowledge this is the first nationwide study in our country that evaluates the rate of response to anti-TNF therapy.

Failure to Anti-TNF treatment may occur due to primary non-response, secondary loss of response in course of treatment, or occurrence of adverse drug related reactions. The incidence of primary nonresponse to AntiTNF therapy varies between clinical trials, ranging from $10 \%$ to $30 \% .^{6,20-22}$ In this study, we found that almost $16 \%$ of patients were primary non responder. While the number of non-responders were slightly higher in CD group compared to UC group, but the difference did not reach a significant level. Billiet and colleagues in a wellcharacterized cohort of 201 anti-TNF naive CD patients, demonstrated the incidence of primary non-response to IFX to be $8 \% .{ }^{23}$ In a retrospective study evaluating the response rate to IFX therapy in refractory UC patients, the non-response rate was $18 \%$ at week $8 .{ }^{24}$ However, the primary non- response rate as high as $30 \%$ to IFX, in moderate to severe UC, has been reported by Rutgeerts and his colleagues. ${ }^{25}$ Although we cannot completely explain the relatively lower percent of primary non responders in our study, but the time frame of patient's evaluation might be, at least partially, responsible for this observation. The definition of primary nonresponse varies across IBD trials 14 but the accepted clinical definition is the failure to achieve initial clinical response with induction therapy leading to discontinuation of the drug. ${ }^{21}$ Recent data imply that successful induction of remission may gradually increase after 3 IFX infusions at weeks 0,2 and 6, or after 3-5 bi-weekly ADA injection. ${ }^{26}$ Therefore, assessment of lack of response should be made after completion of induction therapy; meaning week 14 following initial infusions with IFX and 12 following ADA.,27-28 Accordingly, in this study the failure to induction therapy defined as discontinuation of anti-TNF agent due to requirement for additional therapies or switching to the other TNF blocking agent was based on this time frame. This might be regarded as one of the reasons behind low percent of primary non response in this study compared to other studies.

In this study, almost $17 \%$ of patients gradually lose their response to Anti-TNF therapy during one year of maintenance therapy. Many studies reported that drug discontinuation due to loss of response happens in 5-13\% of patients. ${ }^{7-9,11-13}$ A systematic review performed on 955 primary responder CD patients, demonstrated that mean percentage of patients who lost response to ADA was $18.2 \% .{ }^{14}$ In some studies, the secondary loss of response to IFX was reported to be as low as $7.9 \% .^{15}$ All these studies are in line with our findings regarding the rate of secondary loss of response. Although we have to mention that there are other definitions rather than discontinuation of drug, for secondary loss of response, such as those requiring dose intensification or using clinical symptom indices to define response and remission. In this study we used the discontinuation of drug consumption as an index of loss of response. We have to stress that due to this definition, we might not capture all patients who experienced secondary loss of response.

In this study, about $67 \%$ of our patients continued to receive Anti-TNF therapy beyond 52 weeks. We regarded 
these patients as responder to Anti-TNF therapy. In a large randomized, double-blind, placebo-controlled study of IFX therapy in UC patients, the response rate after one year was $45 \% .{ }^{16}$ It is clear that the tools used to measure response to anti-TNF therapy in different studies may considerably change the response rates and therefore a retrospectively collected response measured cannot be considered directly comparable to a blinded prospective large study using objective measurable outcomes. On the other hand, the response rate that we reported in this study comprise both partial and complete response to therapy, as it relayed on global judgment of physician to continue or discontinue the anti-TNF therapy for patients. Therefore, it is understandable that having a less strict definition of remission in addition to retrospective nature of our study may have been the cause of the observed higher response rate as compared to the randomized trials. It should be noted that our patients were anti-TNF naive patients as no biological treatments were available before this time in our country for IBD patients. Some studies have shown that previous anti-TNF therapy might negatively affect the response rate. ${ }^{6,29}$ This might be another reason behind the good response of our patients to induction therapy.

We have to mention that we could not determine a meaningful clinical predictors of clinical response or lack of it in the present study, perhaps because of the open nature of this cohort and retrospective assessment compared with the randomized blinded cohort.

This study had clear limitations that must be considered during the interpretation of its results. It was a retrospective study in which we used physician global assessment to determine primary response, instead of more objective tools such as endoscopy evaluation. Accordingly, the follow-up and decision-making processes might be biased. Moreover, due to retrospective and open nature of this study we could not captures all the anti-TNF related side effects occurred during the course of therapy. Nevertheless, we did not have any report on occurrence of major and serious opportunistic infection or malignancy. These limitations are integrated in this type of real-world studies and come alongside its advantages.

The strength of our study is that this study could be regarded as a real life study, and generally real-life studies often show better results than pivotal studies, as they tend not to be so strict as compared to prospective trials and therefore they tend to be more like the results observe in real clinical practice.

In conclusion, the collective experience from this study confirms the acceptable efficacy of Anti-TNF drugs as a maintenance therapy in refractory IBD patients. The higher rate of response to anti-TNF therapy in this study compared to other randomized trials might be due retrospective nature of study, less strict definition to response and also the fact that all of our patients were naïveanti -TNF patients. It is noteworthy that our cohort is a real-life patient population that includes participants with complicated, long-standing, extremely resistant disease, and reflects real-life follow-up and decision-making process. These findings may be valuable, as this is the first report of Iranian experience with treating refractory moderateto-severe IBD patients with anti-TNF therapy.

\section{ETHICAL APPROVAL}

There is nothing to be declared.

\section{CONFLICT OF INTEREST}

The authors declare no conflict of interest related to this work.

\section{REFERENCES}

1. de Souza HS, Fiocchi C. Immunopathogenesis of IBD: current state of the art. Nat Rev Gastroenterol Hepatol 2016;13:13-27. doi: 10.1038/nrgastro.2015.186.

2. Haag LM, Siegmund B. Intestinal Microbiota and the Innate Immune System - A Crosstalk in Crohn's Disease Pathogenesis. Front Immunol 2015;6:489. doi: 10.3389/ fimmu.2015.00489.

3. Molodecky NA, Soon IS, Rabi DM, Ghali WA, Ferris M, Chernoff $\mathrm{G}$ et al. Increasing incidence and prevalence of the inflammatory bowel diseases with time, based on systematic review. Gastroenterology 2012;142:46-54. e42. doi: 10.1053/j.gastro.2011.10.001.

4. Malekzadeh MM, Vahedi H, Gohari K, Mehdipour P, Sepanlou SG, Ebrahimi Daryani N, et al. Emerging Epidemic of Inflammatory Bowel Disease in a Middle Income Country: A Nation-wide Study from Iran. Arch Iran Med 2016;19:2-15. doi: 0161901/AIM.003.

5. Naghavi M, Abolhassani F, Pourmalek F, Lakeh M, Jafari N, Vaseghi S, et al. The burden of disease and injury in Iran 2003. Popul Health Metr 2009;7:9. doi: 10.1186/1478-7954-7-9. 
6. Hanauer SB, Feagan BG, Lichtenstein GR, Mayer LF, Schreiber S, Colombel JF, et al. Maintenance infliximab for Crohn's disease: the ACCENT I randomised trial. Lancet 2002;359:1541-9. doi:10.1016/S01406736(02)08512-4.

7. Sandborn WJ, van Assche G, Reinisch W, Colombel JF, D'Haens G, Wolf DC, et al. Adalimumab induces and maintains clinical remission in patients with moderate-tosevere ulcerative colitis. Gastroenterology 2012;142:25765. doi: 10.1053/j.gastro.2011.10.032.

8. Sokol H, Seksik P, Cosnes J. Complications and surgery in the inflammatory bowel diseases biological era. Curr Opin Gastroenterol 2014;30:378-84. doi: 10.1097/MOG.0000000000000078.

9. Kim NH, Jung YS, Moon CM, Lee SY, Kim ER, Kim $\mathrm{YH}$, et al. Long-term clinical outcomes of Korean patient with Crohn's disease following early use of infliximab. Intest Res 2014;12:281-6. doi: 10.5217/ ir.2014.12.4.281.

10. Neurath MF. Cytokines in inflammatory bowel disease. Nat Rev Immunol 2014;14:329-42. doi: 10.1038/nri3661.

11. Mozaffari S, Nikfar S, Abdolghaffari AH, Abdollahi M. New biologic therapeutics for ulcerative colitis and Crohn's disease. Expert Opin Biol Ther 2014;14:583600. doi: 10.1517/14712598.2014.885945.

12. Taba Taba Vakili S, Taher M, Ebrahimi Daryani N. Update on the management of ulcerative colitis. Acta Med Iran 2012;50:363-72.

13. Allez M, Karmiris K, Louis E, Van Assche G, Ben-Horin S, Klein A, et al. Report of the ECCO pathogenesis workshop on anti-TNF therapyfailures in inflammatory bowel diseases: definitions, frequency and pharmacological aspects. J Crohns Colitis 2010;4:355-66. doi: 10.1016/j.crohns.2010.04.004.

14. Ben-Horin S, Chowers Y. Review article: loss of response to anti-TNF treatments in Crohn's disease. Aliment Pharmacol Ther 2011;33:987-95. doi: 10.1111/j.13652036.2011.

15. Seo HI, Park DI, Kim TO, Kim YS, Lee SH, Kim JW, et al. The effect of infliximab on patients with ulcerative colitis in Korea. Intest Res 2014;12:214-20. doi: 10.5217/ir.2014.12.3.214.

16. Lin WC, Chou JW, Yen HH, Hsu WH, Lin HH, Lin JK, et al. Outcomes of limited period of adalimumab treatment in moderate to severe Crohn's disease patients: Taiwan Society of Inflammatory Bowel Disease Study. Intest Res 2017;15:487-94. doi: 10.5217/ir.2017.15.4.487.

17. Aardoom MA, Veereman G, de Ridder L. A Review on the Use of Anti-TNF in Children and Adolescents with Inflammatory Bowel Disease. Int $J$ Mol Sci 2019;20: E2529. doi: 10.3390/ijms20102529.

18. Armuzzi A, Biancone L, Daperno M, Coli A, Pugliese $\mathrm{D}$, Annese $\mathrm{V}$, et al. Adalimumab in active ulcerative colitis: A "real-life" observational study. Dig Liver Dis 2013;45:738-43. doi: 10.1016/j.dld.2013.03.018.
19. Atkins C, Malaise M, Sany J, Russell AS, van Riel PL. Efficacy and safety of adalimumab as monotherapy in patients with rheumatoid arthritis for whom previous disease modifying antirheumatic drug treatment has failed. Ann Rheum Dis 2004;63:508-16. doi:10.1136/ $\operatorname{ard} .2003 .013052$.

20. Bar-Yoseph H, Levhar N, Selinger L, Manor U, Yavzori M, Picard O, et al. Early drug and anti-infliximab antibody levels for prediction of primary nonresponse to infliximab therapy. Aliment Pharmacol Ther 2018 ;47:212-18. doi: 10.1111/apt.14410.

21. Sprakes MB, Ford AC, Warren L, Greer D, Hamlin J. Efficacy, tolerability, and predictors of response to infliximab therapy for Crohn's disease: a large single centre experience. J Crohns Colitis 2012;6:143-53. doi: 10.1016/j.crohns.2011.07.011.

22. Papamichael K, Gils A, Rutgeerts P, Levesque BG, Vermeire $\mathrm{S}$, Sandborn WJ, et al. Role for therapeuticdrug monitoring during induction therapy with TNF antagonistsin IBD: evolution in the definition and management of primary nonresponse. Inflamm Bowel Dis 2015;21:182-97. doi: 10.1097/MIB.0000000000000202.

23. Billiet T, Cleynen I, Ballet V, Claes K, Princen F, Singh S, et al. Evolution of cytokines and inflammatory biomarkers during infliximab induction therapy and the impact of inflammatory burden on primary response in patients with Crohn's disease. Scand J Gastroenterol 2017;52:108692. doi: 10.1080/00365521.2017.1339825.

24. Jakobovits SL, Jewell DP, Travis SP. Infliximab for the treatment of ulcerative colitis: outcomes in Oxford from 2000 to 2006. Aliment Pharmacol Ther 2007;25:105560. doi: 10.1111/j.1365-2036.2007.03300.x

25. Rutgeerts P, Sandborn WJ, Feagan BG, Reinisch W, Olson A, Johanns J, et al. Infliximab for induction and maintenance therapy for ulcerative colitis. $N \mathrm{Engl} \mathrm{J} \mathrm{Med}$ 200;353:2462-76. doi: 10.1056/NEJMoa050516.

26. D'Haens GR, Panaccione R, Higgins PD, Vermeire S, Gassull M, Chowers Y, et al. The London Position Statement of the World Congress of Gastroenterology on Biological Therapy for IBD with the European Crohn's and Colitis Organization: when to start, when to stop, which drug to choose, and how to predict response? Am J Gastroenterol 2011;106:199-212; quiz 213. doi: 10.1038/ajg.2010.392.

27. Sands BE, Anderson FH, Bernstein CN, Chey WY, Feagan BG, Fedorak RN. Infliximab maintenance therapy for fistulizing Crohn's disease. $N$ Engl J Med 2004;350:876-85. doi: 10.1056/NEJMoa030815

28. Yanai H, Hanauer SB. Assessing response and loss of response to biological therapies in IBD. Am J Gastroenterol 2011;106:685-98. doi: 10.1038/ajg.2011.103.

29. Gisbert JP, Marín AC, McNicholl AG, Chaparro M. Systematic review with meta-analysis: the efficacy of a second anti-TNF in patients with inflammatory bowel disease whose previous anti-TNF treatment has failed. Aliment Pharmacol Ther 2015;41: 613-23. doi: 10.1111/apt.13083. 